\title{
CANDIDATOS FUERTES EN LA CONCERTACIÓN ¿SEGURO PARA SUBCAMPEONES O PREVALENCIA DE LOS DOS TERCIOS?*
}

\section{Carolina Garrido y Patricio Navia}

\begin{abstract}
Los autores ofrecen una explicación alternativa de un artículo de Carey y Siavelis que sugiere que la Concertación presenta listas en las elecciones parlamentarias con dos candidatos fuertes debido a que, en tanto coalición de gobierno, puede ofrecer 'seguros' —en la forma de nombramientos en puestos del Ejecutivo- a aquellos candidatos que, asumiendo un riesgo personal en favor de la coalición de centro-izquierda, no salgan electos. Dado que al momento en que Carey y Siavelis escribieron el artículo se esperaba que las presidenciales de 2005 estuvieran más marcadas por la incertidumbre sobre el resultado, ellos argumentaron que "la Concertación no podrá seguir garantizándoles a sus candidatos (...) un cargo en el aparato de gobierno". Eso se traduciría en una mayor dificultad para presentar duplas de candidatos fuertes. Carolina Garrido y Patricio Navia
\end{abstract}

Carolina Garrido Silva. Estudiante de $4^{\circ}$ año de ciencia política en la Universidad Diego Portales y presidenta de la Federación de Estudiantes de la Universidad Diego Portales.

Patricio Navia. Profesor asistente del General Studies Program de New York University. Profesor de la Facultad de Ciencias Sociales e Historia de la Universidad Diego Portales. Ha publicado artículos en las revistas Comparative Political Studies, Journal of Democracy, Democratisation y Social Science Quarterly. También ha publicado capítulos en diversos libros sobre democratización, diseño institucional y leyes electorales. En Chile, ha sido publicado en Estudios Públicos, Perspectivas, Revista de Ciencia Política, el anuario de la FLACSO y es columnista de La Tercera y Revista Capital. Es autor del libro Las Grandes Alamedas. El Chile post Pinochet.

* Agradecemos las sugerencias y comentarios de un árbitro anónimo y las conversaciones sobre este tema con John Carey y Peter Siavelis.

Estudios Públicos, 99 (invierno 2005). 
plantean en este trabajo dos explicaciones alternativas de por qué la Concertación presenta listas con más candidatos fuertes que la Alianza. La primera consiste en que la Concertación está formada por partidos que representan a dos de los tres tercios históricos de la política chilena. La segunda sugiere que la Concertación simplemente está compuesta de un número superior de partidos que la Alianza. Pese a que se encuentra suficiente evidencia para legitimar ambas explicaciones, no hay suficiente confianza estadística o metodológica para sostener que las explicaciones alternativas son mejores que las ofrecidas por Carey y Siavelis. Pero, de la misma forma, se demuestra que la explicación planteada por ellos no es metodológica o estadísticamente más plausible que las planteadas en este estudio.

\section{$\boldsymbol{E}_{\text {n este artículo ofrecemos una explicación alternativa a un artícu- }}$} lo de Carey y Siavelis que sugiere que la Concertación presenta listas en las elecciones parlamentarias con dos candidatos fuertes debido a que, en tanto coalición de gobierno, puede ofrecer 'seguros' —en la forma de nombramientos a puestos del Ejecutivo- a aquellos candidatos que, asumiendo un riesgo personal en favor de la coalición de centro-izquierda, no salgan electos pero contribuyen a mejorar la votación nacional de la coalición. Dado que al momento en que Carey y Siavelis escribieron el artículo se esperaba que las presidenciales del 2005 estuvieran más marcadas por la incertidumbre sobre el resultado, ellos argumentaron que "la Concertación no podrá seguir garantizándoles a sus candidatos (...) un cargo en el aparato de gobierno". Eso se traduciría en una mayor dificultad para presentar duplas de candidatos fuertes. Nosotros presentamos dos explicaciones alternativas de por qué la Concertación presenta listas con más candidatos fuertes que la Alianza. La primera plantea que la Concertación está formada por partidos que representan a dos de los tres tercios históricos de la política chilena. La segunda sugiere que la Concertación simplemente está compuesta de un número superior de partidos que la Alianza. Pese a que encontramos suficiente evidencia para respaldar ambas explicaciones, no logramos suficiente confianza estadística o metodológica para sostener que las explicaciones alternativas son mejores que las ofrecidas por Carey y Siavelis. Pero, de la misma forma, la explicación planteada por ellos no es ni metodológica ni estadísticamente más plausible que las planteadas por nosotros.

En lo que sigue, primero discutimos los incentivos del sistema electoral, subrayando que aunque las coaliciones preferirían tener dos candidatos fuertes por distrito para obtener una votación más alta, los candidatos prefieren tener compañeros de fórmula relativamente débiles. A continuación discutimos cómo efectivamente la Concertación presenta más candida- 
tos fuertes en una cantidad superior de distritos desde 1989 hasta el 2001 que la Alianza por Chile. Luego de resumir los planteamientos de Carey y Siavelis, ofrecemos dos explicaciones alternativas, las verificamos con datos empíricos y terminamos concluyendo que aunque nuestras explicaciones no tienen mayor capacidad de predicción que la planteada por Carey y Siavelis, sí tienen al menos igual validez como potenciales explicaciones para el hecho de que la Concertación haya presentado más candidatos fuertes en las elecciones parlamentarias en Chile entre 1989 y 2001.

\section{El sistema binominal y las listas de dos candidatos}

La Constitución de 1980 establece que la Cámara de Diputados está compuesta por 120 miembros, mientras que el Senado se constituye por 38 senadores democráticamente electos. Como cada circunscripción senatorial y cada distrito para la Cámara de Diputados escogen dos escaños, el sistema electoral chileno es conocido como Sistema Binominal.

Este sistema permite a los partidos formar coaliciones electorales ${ }^{1}$. Éstas pueden presentar listas con un máximo de dos candidatos para competir por los dos escaños disponibles en cada distrito electoral. Ya que estas listas son abiertas, cada elector indica su preferencia por un candidato específico dentro de cualquier lista. El total de votos obtenidos por ambos candidatos en la lista se suma para determinar cuantos escaños le corresponderá a la coalición. Por este motivo, aunque los votos se contabilizan individualmente, los escaños se asignan a las coaliciones. De ahí que lo importante sea obtener la mayor cantidad de votos por lista que sea posible para poder así doblar a la lista que está en segundo lugar y obtener ambos escaños.

Por cierto, son elegidos ambos candidatos de una misma lista cuando ésta alcanza el mayor número de sufragios y además obtiene más del doble de los votos que la lista que la sigue en número de sufragios. Si la lista con mayor número de votos no logra "doblar", obtiene un escaño cada una de las listas que obtengan las dos más altas mayorías de votos, siendo elegidos aquellos candidatos que obtuvieron más votos dentro de sus listas.

La negociación para la formación de duplas por coalición (para 60 distritos de diputados y 9 ó 10 circunscripciones senatoriales) es un momento determinante para predecir el desempeño electoral de cada conglome-

${ }^{1}$ La autorización para formar coaliciones electorales multipartidistas data de la Ley 18.799 de abril de 1989, que modificó la Ley Orgánica Electoral Sobre Votaciones Populares y Escrutinios ( $\mathrm{N}^{\circ}$ 18.700). Ver Allamand (1999). 
rado. Al conformar las listas existen dos estrategias posibles para las coaliciones: se puede pretender obtener los dos escaños o sólo uno. En el primer caso, una coalición puede presentar dos candidatos fuertes que logren doblar a la lista que está en segundo lugar o un candidato fuerte que logre obtener suficientes sufragios para doblar a las otras listas y arrastrar con sus votos a su compañero de fórmula. En el segundo caso, una coalición puede presentar un candidato fuerte que logre por sí solo asegurar un escaño o dos candidatos más débiles que, en conjunto, logren suficientes votos para asegurar un escaño.

Ahora bien, un candidato poderoso preferirá tener un compañero de lista débil para poder asegurarse su cupo en el Congreso. Aun si el objetivo del candidato es contribuir a que su lista obtenga los dos escaños, siempre será mejor tener un compañero de fórmula que vaya a sacar menos votos para así asegurar para sí mismo el primer escaño asignado a su coalición. Pero cuando la coalición pretende doblar a las listas contendoras en la mayor cantidad de distritos o circunscripciones posible, para así lograr una mayoría de los escaños en la Cámara, ésta necesariamente tiene que buscar una dupla de candidatos lo suficientemente "fuertes" para lograr suficientes votos para 'doblar' a todas las otras listas electorales y así asegurar los dos escaños en dicho distrito. En este punto surge el conflicto de intereses de las coaliciones y los aspirantes a candidatos. Las coaliciones prefieren tener 2 candidatos fuertes para lograr doblar la votación de las listas contendoras, obtener ambos escaños y así aspirar a lograr una mayoría en la Cámara. Por su parte, cada candidato privilegia y vela por su interés de obtener el escaño para sí mismo, lo que lo lleva a preferir un acompañante de lista débil. La presencia de 2 candidatos fuertes en una lista fomenta la competencia interna, independientemente de si la coalición puede o no obtener los dos escaños en ese distrito. Comprensiblemente, todos los candidatos preferirían no tener competencia dentro de sus listas para así asegurarse el escaño que, con alta probabilidad, obtendrá su coalición.

Intentando explicar esta contradicción, Carey y Siavelis (2003) señalan que la Concertación ha resuelto el problema de intereses divergentes mediante un 'seguro' para aquellos candidatos que corren un riesgo personal a favor de la coalición. Dicho seguro se traduce en un cargo en el gobierno. Como la Concertación tenía claras posibilidades de victoria en las elecciones presidenciales de 1989 y 1993, y controlaba el Ejecutivo para las parlamentarias de 1997, estaba en condiciones de ofrecer 'seguros' a sus candidatos al Legislativo que se arriesgaran a competir y no lograran ganar escaños. A diferencia de la derecha, la Concertación podía ofrecer con rela- 
tiva certeza la posibilidad de premiar a aquellos candidatos derrotados ('subcampeones', en la terminología de Carey y Siavelis) con puestos en el Ejecutivo. En su estudio, Carey y Siavelis muestran evidencia de que la Concertación premió a sus 'subcampeones' con cargos en el poder Ejecutivo durante el período 1993-1997. Es más, al relacionar la votación que obtuvo cada candidato, Carey y Siavelis muestran que mientras más cerca estuvieron de una victoria, más posibilidades tenían los subcampeones de recibir un 'seguro' por parte del gobierno controlado por la Concertación.

Antes de abocarnos al análisis de los argumentos de Carey y Siavelis, mostramos evidencia del fenómeno que ellos estudian: la presencia de un número mayor de candidatos fuertes en la Concertación que en la Alianza por Chile. El Cuadro $\mathrm{N}^{\circ} 1$ presenta detalles de todos los distritos donde las dos coaliciones presentaron dos candidatos en las elecciones del período 1989-2001 (Carey y Siavelis estudian sólo las elecciones del período 1989-1997). Para evaluar la presencia de candidatos fuertes, usamos la misma herramienta utilizada por Carey y Siavelis: la razón matemática entre el candidato con más votos y el candidato con menos votos de la coalición. Esto es, dividimos la votación del candidato más votado por la votación del candidato menos votado de la coalición. Esa cifra varía entre un mínimo

CUADRO No 1 : RAZÓN DE 1\%/2º LUGAR EN ELECCIONES LEGISLATIVAS, 1989-2001

\begin{tabular}{|c|c|c|c|c|c|}
\hline $\begin{array}{l}\text { Año de } \\
\text { elección }\end{array}$ & $\begin{array}{l}\text { Número de } \\
\text { distritos con } \\
2 \text { candidatos }\end{array}$ & $\begin{array}{c}\text { Promedio de razón } \\
\text { primero/ } \\
\text { segundo }\end{array}$ & $\begin{array}{l}\text { Promedio } \\
\text { de desviación } \\
\text { estándar }\end{array}$ & $\begin{array}{c}\text { Valor } \\
\text { mínimo }\end{array}$ & $\begin{array}{c}\text { Valor } \\
\text { máximo }\end{array}$ \\
\hline
\end{tabular}

\begin{tabular}{|c|c|c|c|c|c|}
\hline \multicolumn{6}{|c|}{ Alianza } \\
\hline 1989 & 59 & 3,67 & 4,73 & 1,02 & 25,25 \\
\hline 1993 & 60 & 4,29 & 3,91 & 1,04 & 18,76 \\
\hline 1997 & 59 & 5,24 & 5,91 & 1,02 & 29,07 \\
\hline 2001 & 59 & 4,74 & 4,97 & 1,03 & 24,52 \\
\hline 1989-2001 & 237 & 4,49 & 4,93 & 1,02 & 29,07 \\
\hline \multicolumn{6}{|c|}{ Concertación } \\
\hline 1989 & 56 & 2,45 & 2,50 & 1,03 & 13,34 \\
\hline 1993 & 60 & 2,47 & 2,40 & 1,00 & 16,12 \\
\hline 1997 & 60 & 2,19 & 1,66 & 1,01 & 10,46 \\
\hline 2001 & 60 & 3,05 & 4,28 & 1,00 & 30,30 \\
\hline 1989-2001 & 236 & 2,54 & 2,88 & 1,00 & 30,30 \\
\hline
\end{tabular}

Fuente: Elaboración de los autores con datos de www.elecciones.gov.cl 
marginalmente superior a 1 (cuando ambos candidatos obtuvieron casi la misma votación) y cualquier número entero positivo. Nótese que la definición de 'fuerte' puede ser engañosa. La herramienta utilizada por los autores permite que una lista con un candidato que obtiene $10 \%$ de los votos y otro que obtiene $1 \%$ tenga el mismo valor que una lista donde un candidato obtiene $40 \%$ y otro $4 \%$.

Como lo muestra el Cuadro $\mathrm{N}^{\circ}$ 1, la razón primero/segundo fue siempre superior en la Alianza por Chile que en la Concertación. Mientras en la Concertación ese valor promedio sólo superó la barrera de 3 en 2001, en la Alianza fue siempre superior a 3, aunque adquirió el valor más alto en 1997. Esto quiere decir que efectivamente la Concertación presentó más candidatos fuertes que la Alianza en todas las contiendas parlamentarias celebradas desde el retorno de la democracia. Pero el Cuadro $\mathrm{N}^{\circ} 1$ también muestra que la cantidad de duplas fuertes que presentó cada coalición varió a través del tiempo (este asunto lo discutimos en detalle más abajo).

Nótese que mientras la Concertación presentó en general un promedio inferior de razón primero/segundo (esto es, la Concertación tuvo más duplas fuertes que la Alianza), la desviación estándar en la Alianza fue mayor que en la Concertación, lo que subraya que hubo mayor variedad en la Alianza entre duplas fuertes y duplas con un candidato débil. Mientras en la Alianza la razón promedio para las cuatro elecciones parlamentarias fue de 4,49 con una desviación estándar de 4,93, en la Concertación el promedio fue de 2,54, con una desviación estándar de sólo 2,88. Esto quiere decir que mientras en la Concertación dos tercios de las competencias en los 236 distritos tuvieron valores entre 1 y 5,42, en la Alianza dos tercios de las competencias tuvieron valores entre 1 y 9,42.

Carey y Siavelis (2003: 10) muestran que la Concertación ha logrado obtener los dos escaños en 31 distritos en las elecciones celebradas entre 1989 y 1997 (11 en 1989 y 1993, 10 en 1997), mientras que la derecha logró obtener los dos escaños en un distrito en 1993 y 1997². Podemos añadir que en 2001 la Concertación dobló en 4 distritos, mientras que la Alianza hizo lo propio en 1 distrito. De esta forma, el número de subcampeones de la Concertación ha fluctuado entre un mínimo de 45 en 1989 y un máximo de 58 en 2001.

${ }^{2}$ Hay tres errores en la Tabla 1 de Carey y Siavelis (2003:10), donde reportan que la derecha no dobló en ningún distrito en 1997. De hecho, la coalición de derecha dobló en el distrito 23 tanto en 1993 como en 1997 (también en 2001, pero esa elección no fue estudiada por estos autores). A su vez, la Concertación dobló en 10 distritos en 1997, no en 11 como señalan Carey y Siavelis. 
CUADRO N ${ }^{\circ} 2: \quad$ RESULTADOS DE COMPETENCIAS ENTRE COALICIONES A NIVEL DISTRITAL EN ELECCIONES PARLAMENTARIAS, 1989-2001

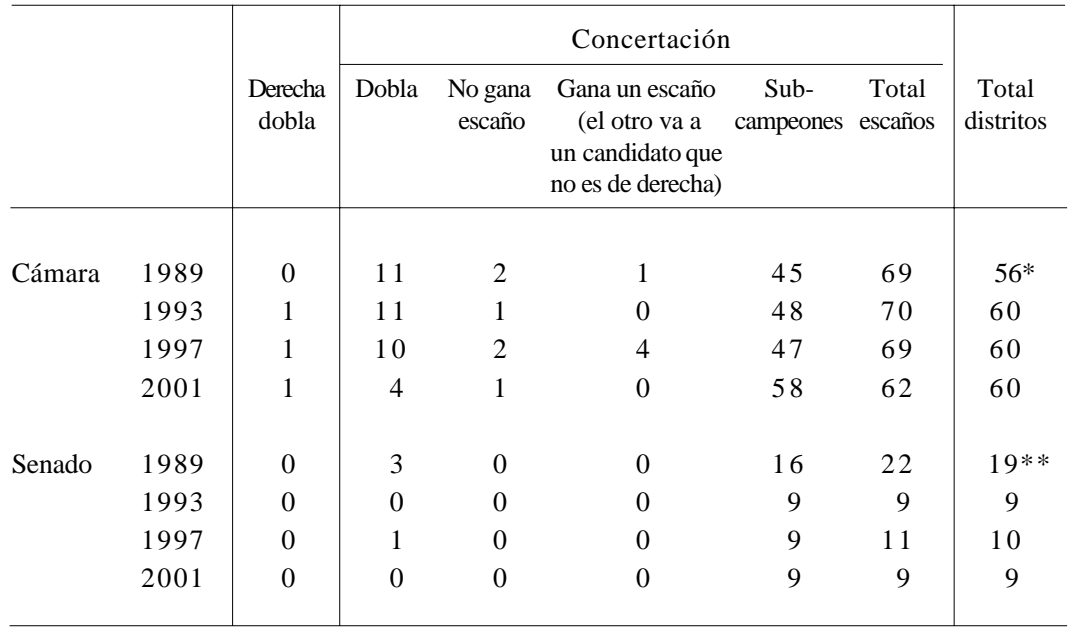

* En 4 distritos la Concertación presentó sólo un candidato.

** En 1989 hubo elecciones en 19 circunscripciones senatoriales; en 1993 y 2001 hubo elecciones en 9 circunscripciones senatoriales, mientras que en 1997 hubo elecciones en 10 circunscripciones.

Fuente: Carey y Siavelis (2003) y elaboración propia.

Aquí planteamos que el argumento basado en el 'seguro' para los subcampeones no es necesario - y tampoco suficiente- para explicar la formación de duplas fuertes en las listas de la Concertación. Hay variables históricas y empíricas alternativas que explican igualmente bien los motivos por los que la Concertación tiene mayor facilidad y está en mejores condiciones que la Alianza para presentar un número mayor de candidatos fuertes. El número de partidos que conforman la coalición y las características de esos partidos como representantes del centro y de la izquierda política pueden explicar por sí solos que la Concertación presente dos candidatos fuertes en cada distrito. En lo que sigue analizamos primero la explicación histórica que da cuenta de la Concertación como una coalición que reúne a la izquierda y al centro. Luego discutimos cómo el número de partidos que componen la Concertación — superior al número de partidos que componen la Alianza por Chile - está positivamente relacionado con la cantidad de candidatos fuertes que presenta cada una de esas coaliciones. 


\section{Primera hipótesis: \\ La Concertación es la suma del centro y la izquierda}

La literatura sobre la evolución del sistema político y de partidos en Chile es abundante y variada, pero sorprendentemente exenta de grandes debates respecto a la naturaleza y características del orden político partidista en el país hasta el quiebre democrático de 1973 (Scully, 1992; Tironi y Agüero, 1999; Valenzuela, 1978; Valenzuela, 1995; Valenzuela, 1999; Valenzuela y Scully, 1997; Urzúa Valenzuela, 1992). Aunque existen debates sobre las características del sistema de partidos con posterioridad al plebiscito de 1988 (ver sobre todo Tironi y Agüero, 1999; Valenzuela, 1999), hay un amplio consenso sobre la naturaleza de un sistema político multipartidista moderado con tendencia a la polarización antes del quiebre democrático (Gil, 1969; Sartori, 1976; Garretón, 1983). La división del sistema de partidos en tres tercios (derecha, centro e izquierda) es ampliamente aceptada por todos aquellos que estudian el sistema de partidos y la democracia chilena pre 1973.

Dentro de ese marco general se han propuesto diferentes explicaciones para dar cuenta del desarrollo político en la segunda mitad del siglo XX. Por ejemplo, Scully (1992) argumenta que la transformación y polarización del sistema de partidos entre 1952 y 1958 se debió al conflicto clericalanticlerical y al conflicto de clases en el sector rural y urbano. De dicho conflicto surgió un nuevo partido que se posicionó en el centro político, el Partido Demócrata Cristiano (PDC). Con su aparición, el país temporalmente se dividió en cuatro sectores: la Izquierda constituida por la coalición PS-PC (bajo las siglas FRAP en las presidenciales de 1958), un Centro cristiano constituido por el PDC, un Centro laico representado por el PR y una Derecha tradicional dividida entre el Partido Liberal y el Partido Conservador. En 1962, el PR viró hacia la derecha (aunque eventualmente una buena parte de ese partido, incluido su liderazgo, emigró hacia la izquierda allendista), dejando libre el centro para el PDC, que en las presidenciales de 1964 y las parlamentarias de 1965 se consolidó como partido de centro altamente polarizado e ideológico. Producto de este cambio en el centro y de la movilización masiva del electorado, entre otras variables, el país quedó dividido en 3 grandes sectores (o tercios), la izquierda, el centro PDC y la derecha.

Después de 1970, producto del ambicioso programa revolucionario del gobierno izquierdista de la Unidad Popular de Salvador Allende, la tradicional división de tres tercios del sistema político se realineó para convertirse, al menos en las parlamentarias de 1973 y durante los meses que precedieron el golpe militar, en una división dicotómica entre los que estaban a favor de la revolución socialista de Allende y los que se oponían 
(Arriagada, 1974; De Vylder, 1976). Así y todo, el sistema partidista al momento del quiebre de la democracia se conformaba de tres grandes sectores con identidad propia e ideologías diferentes. La derecha estaba compuesta por el Partido Nacional (PN), el centro estaba conformado por el PDC y la izquierda estaba formada por el PS, el PC y otros partidos menores (como el MAPU, la Izquierda Cristiana y una facción del PR). Pero como plantean Valenzuela y Scully (1993: 198-199), "el espectro político-partidario chileno se caracterizó, desde mediados de los años treinta hasta el quiebre de la democracia en 1973, no sólo por su división en un segmento de derecha, uno de centro y otro de izquierda, sino a la vez por su carácter multipartidario (...) Aun cuando hubo, en ciertas épocas, hasta treinta partidos en juego, nunca fueron más de cinco o seis los relevantes”. Los tres grandes tercios del sistema político chileno se mantenían constantes, y se conformaban por uno o dos partidos importantes en cada sector.

Ahora bien, la división de los tres tercios tendió a debilitarse en 1973, cuando la derecha y el PDC se unieron en una alianza electoral contra la UP. En las elecciones parlamentarias de 1973, la tradicional división de los tres tercios fue reemplazada por un enfrentamiento entre la izquierda y una coalición electoral del centro y la derecha. Pero con la llegada de la dictadura militar se volvió a producir la división de los tres tercios, con una izquierda en abierta oposición al gobierno militar, un centro que apoyaba condicionalmente $-\mathrm{o}$ al menos daba señales de aquiescencia frente- $-\mathrm{a}$ la dictadura y una derecha que apoyaba abiertamente el nuevo gobierno de facto.

Luego, específicamente a partir de 1983, se comenzó a articular una oposición amplia al régimen de Pinochet que rompió el ordenamiento histórico que separaba por razones ideológicas al tercio de centro con el tercio de izquierda. Una de las primeras iniciativas que logró unir a líderes de izquierda y de centro fue el llamado Grupo de Estudios Constitucionales (Grupo de los 24), una instancia en que estaban presentes la mayoría de las corrientes políticas de centro y de izquierda, a excepción de los comunistas y de la derecha pinochetista. Más tarde, la llegada a la presidencia del PDC del ex ministro de relaciones exteriores del gobierno de Frei Montalva, Gabriel Valdés, facilitó tanto la decisión de ese partido - y del centro político- de constituirse militantemente como oposición a la dictadura y de buscar formar un frente amplio con todos los sectores democráticos- particularmente con la izquierda - , que permitiera poner fin a la dictadura y lograr el retorno de la democracia (Cavallo, Sepúlveda y Salazar, 1997: 341380; Constable y Valenzuela, 1991: 271-295). 
Después de fallidos intentos de negociación con el gobierno de Pinochet, en medio de una ola de protestas populares motivadas por la crisis económica por la que atravesaba el país, las fuerzas democráticas formaron una coalición llamada Alianza Democrática, la que incluía al PDC, varias facciones del entonces dividido PS, diversas facciones asociadas con el PR, el Partido Socialdemócrata y otros grupos, incluidos algunos tradicionalmente asociados con la derecha. Ésta fue la primera instancia formal de lo que se convertiría en la coalición de partidos de izquierda y centro (Boeninger, 1997: 292-346).

Ya para el plebiscito de 1988, y con la aspiración de derrocar a Pinochet, la entonces débil y difícil unión entre el PDC y el PS, los dos partidos más importantes y mejor organizados del centro y la izquierda democrática, cobró suficiente fuerza como para constituirse en una coalición política formal. El objetivo de esta coalición era lograr el retorno de la democracia utilizando los mecanismos que estaban plasmados en la propia constitución diseñada por la dictadura y adoptada en el plebiscito de 1980 (Ortega Frei, 1992; Walker, 1990). Por cierto, varios líderes asociados al socialismo y otros grupos moderados resolvieron crear lo que por entonces consideraron un "partido instrumental” que pudiera permitir superar la restricción legal existente para la formación de un partido propiamente socialista. Así surgió el Partido por la Democracia (PPD), que eventualmente se convirtió en uno de los dos partidos importantes del sector izquierdista de la Concertación.

Junto al PDC, PR y varias facciones socialistas, el PPD formó la Concertación de Partidos por el No antes del plebiscito de 1988. En total fueron 17 partidos y grupos provenientes tanto de la izquierda como del centro (aunque había también unos grupos que se identificaban con la derecha) que se unieron para poner fin a la dictadura de Pinochet a través de la votación popular en octubre de 1988. Aunque la historia de Chile antes había experimentado con coaliciones de centro e izquierda (por ejemplo, los gobiernos radicales de Aguirre Cerda y Ríos), desde la aparición del PDC en la década de los 50 y su consolidación como partido hegemónico de centro a partir de los 60, el centro y la izquierda no habían logrado formar coaliciones. Basta recordar lo difícil que resultó que el PDC se decidiera a votar por Salvador Allende cuando el Congreso nacional hubo de escoger al presidente después que el electorado no entregara su apoyo mayoritario a ninguno de los tres candidatos en las presidenciales de 1970. Por eso que la formación primero de la Alianza Democrática y después de la Concertación de Partidos por el No representó un cambio sustancial en la práctica política observada en el país desde la segunda mitad del siglo XX. 
Después de la victoria del No en el plebiscito de 1988, los partidos de la Concertación fácilmente concordaron en la conveniencia de mantener su alianza política y transformarla en una coalición electoral que enfrentara unida las elecciones presidenciales y parlamentarias de 1989. Así, la Concertación de Partidos por el No se transformó, evolucionó, consolidó y pasó a llamarse Concertación de Partidos Por la Democracia (Otano, 1995: 54-87). Después de las elecciones presidenciales y parlamentarias de 1989, y habiéndose adoptado las reformas constitucionales de junio de 1989 que eliminaban las restricciones a la existencia de los partidos socialistas y comunistas, el número de partidos que conformaban la Concertación disminuyó sustancialmente. Fusiones entre tendencias de un mismo partido (como en el caso del PS y del PR) y la desaparición de otros grupos menores producto de su pobre desempeño electoral ayudaron a reducir considerablemente el número de partidos de la Concertación. De hecho, desde 1994, esta coalición se conforma por 4 partidos con representación parlamentaria: PDC, PS, PPD Y PRSD.

Así, podemos argumentar, junto a Scully y Valenzuela (1993) y Valenzuela (1999) que la Concertación de Partidos por la Democracia engloba a 2 de los 3 tercios que conformaban el sistema partidista hasta 1973. Incluso en forma consistente con una visión opuesta a la de Valenzuela, planteada por Tironi y Agüero (1999), podemos concluir que, irónicamente, por la naturaleza plebiscitaria de la contienda electoral de 1988, el gobierno de Pinochet dejó como herencia una división en el país donde 2 de los 3 tercios históricos se unieron para conformar una oposición democrática al régimen militar. Ya sea porque la Concertación representa una coalición del centro y de la izquierda o porque la división Sí-No permitió que el centro y la izquierda se unieran en un solo bloque, la presencia de un número mayor de candidatos fuertes en la Concertación se explicaría por hechos históricos, independientemente de la posibilidad de ofrecer seguros a los perdedores que pudiera tener la Concertación.

De hecho, el que la Concertación esté integrada por el centro y una buena parte de la izquierda histórica provenientes del antiguo sistema de partidos no sólo facilita sino que hace casi inevitable que, independientemente de cómo se hayan estructurado las preferencias de los electores (ya sea manteniendo los 3/3 o evolucionando hacia un nuevo ordenamiento de 2/2), la unión de ambas fuerzas electorales lleve a la Concertación a presentar una mayor cantidad de candidatos en las elecciones parlamentarias. Esto contribuiría también a que la Concertación tenga más posibilidades que la derecha de presentar duplas fuertes de candidatos. 
CUADRO No 3: $\quad$ PESO ELECTORAL DE PARTIDOS POLÍTICOS CHILENOS POR COALICIÓN, 1961-2001

\begin{tabular}{|c|c|c|c|c|c|c|c|c|c|c|}
\hline Sector & Partido & 1961 & 1965 & 1969 & 1973 & 1989 & 1993 & 1997 & 2001 & $\begin{array}{l}\text { Pro- } \\
\text { medio }\end{array}$ \\
\hline Derecha & $\begin{array}{l}\text { PL, PCo, } \\
\text { PN, RN, } \\
\text { UDI, PSur, } \\
\text { UCC, otros }\end{array}$ & 30,4 & 13,1 & 20,0 & 23,0 & 41,32 & 36,7 & 38,4 & 44,3 & 30,0 \\
\hline Centro & $\begin{array}{l}\text { PDC, PR } \\
\text { (excepto 73), } \\
\text { PADENA, } \\
\text { PRSD, otros }\end{array}$ & 43,7 & 58,8 & 42,8 & 30,3 & 34,5 & 30,1 & 26,1 & 23,0 & 36,2 \\
\hline Izquierda & $\begin{array}{l}\text { PR (73), } \\
\text { PS, PC, } \\
\text { MAPU, IC, } \\
\text { PPD, } \\
\text { PH, otros }\end{array}$ & 22,2 & 22,7 & 30,9 & 43,9 & 22,3 & 32,4 & 34,0 & 29,1 & 29,7 \\
\hline $\begin{array}{l}\text { Total } \\
3 \text { tercios }\end{array}$ & $\begin{array}{l}\text { Derecha, } \\
\text { centro, } \\
\text { izquierda }\end{array}$ & 96,3 & 94,6 & 93,7 & 97,2 & 91,0 & 99,2 & 98,5 & 96,4 & 95,9 \\
\hline
\end{tabular}

Partidos: PL (Partido Liberal), PCo (Partido Conservador), PN (Partido Nacional), RN (Renovación Nacional), UDI (Unión Demócrata Independiente), PR (Partido Radical), PADENA (Partido Demócrata Nacional), PH (Partido Humanista).
PDC (Partido Demócrata Cristiano), PRSD (Partido Radical Social Demócrata), PS (Partido Socialista), PC (Partido Comunista), MAPU (Movimiento de Acción Popular Unitaria), IC (Izquierda Cristiana), PPD (Partido por la Democracia),

Fuentes: 1961-1965: Urzúa Valenzuela (1992: 622); 1969-73: Valenzuela (1978: 85); 1989-2001: http://www.elecciones.gov.cl

Para verificar la continuidad en las votaciones de los electores, comparamos las votaciones de los principales partidos políticos para todas las elecciones parlamentarias entre 1961 y 2001. El Cuadro $N^{\circ} 3$ muestra un sorprendente nivel de continuidad en las preferencias electorales de los 3 sectores. Aunque claramente el tercio derecha ha experimentado una consolidación evidente a partir de 1989, mientras que el tercio centro ha experimentado un declive desde 1965 en adelante, resulta todavía fácil identificar las preferencias electorales de los chilenos con el viejo orden de los tres tercios. El tercio izquierda ha fluctuado entre un 22,2\% en 1961 y un 43,9\% en 1973. 
Si tomamos los promedios para las 8 elecciones parlamentarias celebradas entre 1961 y 2001, nos acercamos bastante a los tres tercios. De hecho, aun si tomamos los promedios sólo para las elecciones posteriores a 1989, los valores son de 38,4\% para el tercio de derecha, 28,4\% para el tercio de centro y $29,5 \%$ para el tercio de izquierda. La persistencia y resistencia de los tres tercios a los efectos de diferentes leyes electorales y distintos ordenamientos de coaliciones políticas — brevemente descritos aquí, pero ampliamente demostrados en la literatura - deberían tenerse presente a la hora de realizar análisis del comportamiento electoral en Chile. La presencia de dos de los tres tercios en la Concertación de Partidos por la Democracia no debiera ser ignorada como un factor explicativo alternativo de por qué esa coalición de gobierno presenta dos candidatos fuertes en las elecciones legislativas a tasas sustancialmente mayores que la coalición de derecha.

Naturalmente, un análisis basado exclusivamente en los datos electorales agregados a nivel nacional resulta excesivamente simplista. Pero al complementarlo con resultados de encuestas efectuadas regularmente durante la década de 1990, estos resultados dejan en evidencia que la tesis de la supervivencia de los tres tercios no debiera ser desechada con demasiada rapidez. En las encuestas regularmente hechas por el Centro de Estudios Públicos (aquí consideramos sólo aquellas realizadas desde el retorno de la democracia en 1990) aparece una pregunta en que se pide a los encuestados que se identifiquen con alguno de los tres sectores en que tradicionalmente se alinearon los partidos y los electores en el país. Como muestra la Figura $\mathrm{N}^{\circ} 1$, entre junio de 1990 y junio del 2004, la cantidad de personas que dicen identificarse con la izquierda ha fluctuado entre poco más de $35 \%$ y poco menos de $20 \%$. A su vez, los que dicen identificarse con la Derecha han fluctuado entre poco menos del $15 \%$ y poco más del $25 \%$, con una clara tendencia al alza a partir de 1990. Aquellos que dicen identificarse con el centro han mostrado una tendencia a la baja a partir de 1990, alcanzando un máximo sobre el $30 \%$ a comienzos de la década de los 90 y manteniéndose entre el 10 y el 15\% a partir de 1998 (ver también los cuadros del CERC en Huneeus, 2003: 238). Aunque uno podría sugerir que el número de aquellos que dicen no identificarse con ninguna de las tres tendencias ha aumentado de menos de $30 \%$ en 1990 a más del $40 \%$ en las últimas encuestas, más de dos tercios de todos los encuestados siguen reconociendo en la tradicional división de los 3/3 un referente válido. Si algo, el único fenómeno que ha tendido a consolidarse durante los años post-dictadura ha sido el debilitamiento del tercio de centro, que pasó de ser el más fuerte a comienzos de los 90 a ser el más débil en los últimos años. Así y todo, una amplia mayoría de 
FIGURA N ${ }^{\circ}$ 1: $\quad$ AUTOIDENTIFICACIÓN CON SECTOR POLÍTICO

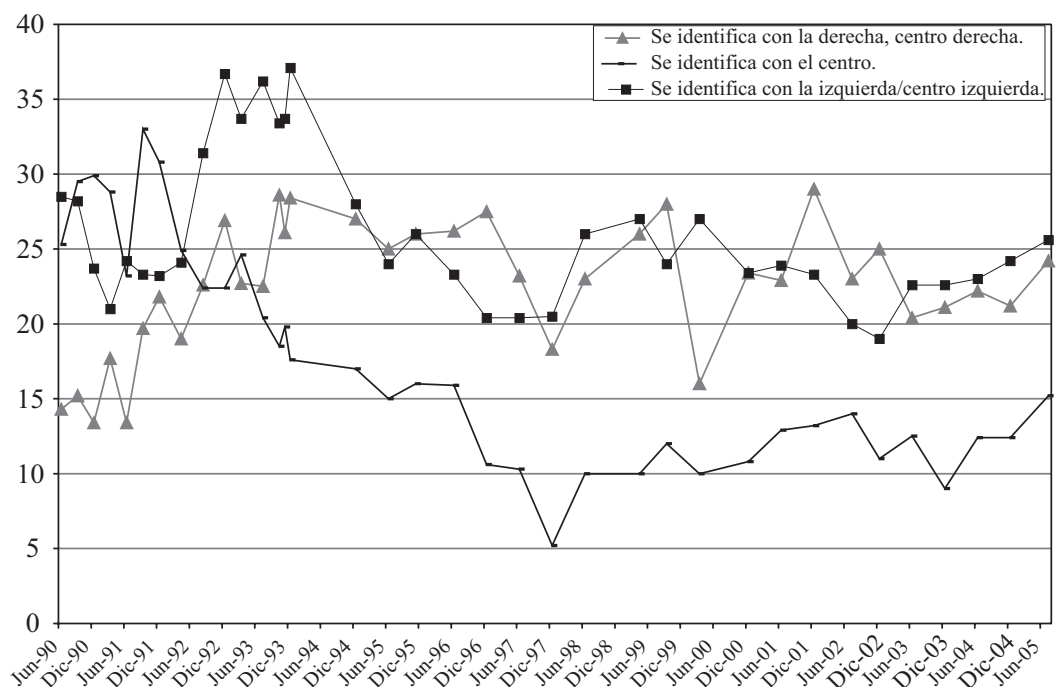

Fuente: Elaboración propia con datos de www.cepchile.cl

los encuestados siguen identificándose con alguno de los tres tercios de la política nacional, evidenciando que las categorías de derecha, centro e izquierda no debieran ser tan fácilmente ignoradas o abandonadas.

Ahora bien, el argumento ampliamente difundido que sugiere que la dicotomía Concertación/Alianza ha reemplazado a los tres tercios históricos se basa también en evidencia de encuestas. Como muestra la Figura $\mathrm{N}^{\circ}$ 2, un número considerable de chilenos se identifica ya sea con la Concertación o con la Alianza. Pero la cantidad de aquellos que dicen sentirse cerca de alguna de las dos coaliciones más importantes del país ha venido en descenso desde 1990. De hecho, si en 1990, más de un 65\% de los encuestados decía identificarse con la Concertación o la Alianza, hacia 2004 poco más del $50 \%$ de los encuestados decía identificarse con alguna de las dos coaliciones.

Si comparamos el porcentaje de aquellos que se siguen identificando con las dos grandes coaliciones con el porcentaje de aquellos que se siguen definiendo respecto a los tres tercios clásicos podemos ver que la división histórica parece mantenerse en el tiempo con más fuerza que la división nacida del plebiscito de 1988. En 1990, un 70\% de la población se 
FIGURA No 2: $\quad$ IDENTIFICACIÓN PERSONAL CON COALICIÓN POLÍTICA, 1994-2005

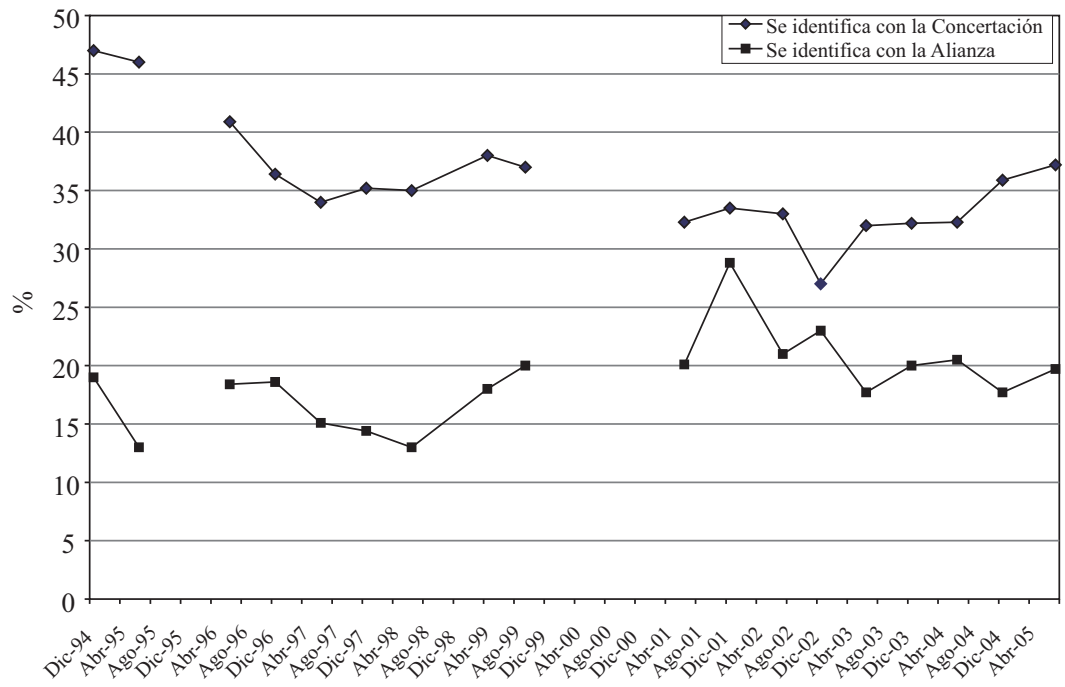

Fuente: Elaboración propia con datos de www.cepchile.cl

identificaba con alguna de las dos grandes coaliciones mientras que un poco menos del $70 \%$ se identificaba con alguno de los tres tercios. Para 2004, más del $60 \%$ se seguía identificando con alguno de los tres tercios, pero sólo alrededor del $50 \%$ se identificaba ya sea con la Concertación o con la Alianza. Esto quiere decir que los tres tercios han logrado mantenerse como un referente de identificación política con más éxito que la división Concertación/Alianza, al menos en las encuestas producidas por el Centro de Estudios Públicos.

Naturalmente, será difícil sugerir a partir de estos datos que los tres tercios son más fuertes y duraderos que la división Concertación/Alianza. Pero para el objeto de este artículo basta con plantear que no hay evidencia suficiente para argumentar que los tres tercios han perdido relevancia histórica. Por lo tanto, nos parece injustificado descartar la posibilidad de que la Concertación siga representando dos de los tres tercios históricos. Y por lo tanto nos parece también aventurado desconocer la posibilidad de que la presencia de duplas fuertes en las listas electorales de la Concertación pudiera ser el resultado de que la coalición de gobierno continúa representando a dos de los tres tercios históricos en que se ha dividido políticamente el sistema de partidos y el electorado en el país desde mediados de siglo XX. 


\section{Segunda hipótesis: \\ Número de partidos en la Concertación y la Alianza}

Además de la explicación histórica discutida en la sección anterior, argumentamos que otro posible motivo por el que la Concertación presenta listas con dos candidatos fuertes responde a que dicha coalición está formada por un número de partidos superior a los que componen la coalición de la derecha. Esto es, tal vez la Concertación presenta listas con más candidatos fuertes simplemente porque hay más partidos en esa coalición que en la coalición de derecha. La hipótesis a considerar en esta sección es que a mayor cantidad de partidos en la coalición, mayor cantidad de duplas fuertes.

\subsection{Seguro para subcampeones en la Concertación}

Para poder medir si sólo el número de partidos es relevante a la hora de conformar las duplas, hemos construido una base de datos similar a la utilizada por Carey y Siavelis. Nuestra base de datos incluye a todas las parejas de candidatos de la Concertación para todas las elecciones para la Cámara de Diputados entre 1989 y 2001. Hemos creado la variable RazónConcertación, que consiste en la división de los votos del candidato que obtiene la primera mayoría por los votos alcanzados por el candidato que logró la segunda mayoría en la lista. A partir de dicha variable obtenemos el promedio de las diferencias entre las parejas de candidatos presentadas por distrito por la Concertación. En forma conjunta, reportamos el número de partidos que conformaban esta coalición para cada una de las elecciones señaladas. Para confirmar nuestra hipótesis, la Razón-Concertación debiera ser mayor mientras menos partidos haya en la coalición. Esto es, mientras más partidos haya en la Concertación, mayor debería ser la posibilidad de que esa coalición presente más de un candidato fuerte en cada uno de los distritos y circunscripciones electorales.

El Cuadro No 4 muestra el promedio de la Razón-Concertación para cada elección de la Cámara de Diputados llevada a cabo desde 1989, junto con el número de partidos que conformaron la Concertación cada año. En 1989, la Concertación se conformó de 7 partidos que presentaron candidatos a la Cámara de Diputados: PDC, PR, PPD, Partido Humanista (PH), Partido Verde (PV), PS (aunque algunos de sus candidatos iban como PPD, una buena parte iba como independientes en la lista Concertación) e Independientes (militantes de partidos menores, que para efectos de nuestro análisis agrupamos en un solo partido). Con 7 partidos como base en 1989, esta coalición presenta como Razón-Concertación (votos del candidato que ob- 
RAZÓN-CONCERTACIÓN Y NÚMERO DE PARTIDOS DE LA CONCERTACIÓN, 1989-2001

\begin{tabular}{lcccc}
\hline & $\begin{array}{c}\text { Razón-Conc. } \\
1989\end{array}$ & $\begin{array}{c}\text { Razón-Conc. } \\
1993\end{array}$ & $\begin{array}{c}\text { Razón-Conc. } \\
1997\end{array}$ & $\begin{array}{c}\text { Razón-Conc. } \\
2001\end{array}$ \\
\hline Promedio & 2,451 & 2,475 & 2,198 & 3,057 \\
Número de partidos & 7 & 6 & 5 & 5
\end{tabular}

Fuente: Cálculos de los autores con datos obtenidos de http://www.elecciones.gov.cl

tuvo el primer lugar dividido por los votos del candidato que obtuvo el segundo lugar) igual a 2,451.

En 1993 la Concertación modificó su base partidista. Ese año se desligaron de la Concertación tanto el PH como el PV (entonces unidos en una agrupación llamada Alianza Humanista Verde), mientras que se sumó el Partido Socialdemócrata (PSD) y formalmente se unió el PS. La doble militancia entre el PS y el PPD llegó a su fin en 1992, por lo que los partidos que conformaban la alianza de gobierno ese año fueron el PDC, PR, PSD, PPD, PS e independientes. Aunque hubo un partido menos, la Razón-Concertación en 1993 aumentó levemente respecto de 1989. Pero hacia fines de 1997, a dos años del término del mandato presidencial del DC Eduardo Frei, la Concertación, con un partido menos producto de la fusión del PR con el PSD, disminuyó su Razón-Concertación a 2,198. Por último, en 2001, a cuatro años del término del mandato presidencial del PS-PPD Ricardo Lagos, y con la misma cantidad de partidos que en 1997, la Razón-Concertación aumentó, mostrando su valor más alto para las 4 elecciones celebradas desde el retorno de la democracia.

A pesar de que a simple vista se podría vislumbrar una tendencia al alza, estadísticamente las diferencias entre las razones para cada elección no son significativas. El Cuadro $\mathrm{N}^{\circ} 5$ muestra pruebas t para una muestra para las 4 elecciones parlamentarias del período. Dada la gran varianza que se da entre distritos donde se presentan dos candidatos fuertes y distritos donde se presenta sólo uno, los márgenes de confianza (95\%) son bastante amplios. Así, en 1989, con un 95\% de confianza podemos decir que el verdadero valor de la Razón-Concertación se ubicaba entre un mínimo de 1,78 y un máximo de 3,12. Como es de esperar, los intervalos de confianza para las 4 elecciones se superponen. Esto es, no podemos concluir con confianza estadística que la disminución en el número de partidos de la Concertación haya tenido un efecto significativo en aumentar el número de distritos don- 
CUADRO N ${ }^{\circ}$ 5: $\quad$ PRUEBAS T PARA UNA MUESTRA DE RAZÓN-CONCERTACIÓN, 1989-2001

\begin{tabular}{|c|c|c|c|c|c|c|}
\hline & \multirow[t]{2}{*}{ Valor t } & \multirow[t]{2}{*}{$\begin{array}{c}\text { Grados de } \\
\text { libertad }\end{array}$} & \multirow[t]{2}{*}{$\begin{array}{c}\text { Sig. } \\
\text { (2-tailed) }\end{array}$} & \multirow[t]{2}{*}{$\begin{array}{c}\text { Diferencia } \\
\text { promedio }\end{array}$} & \multicolumn{2}{|c|}{$\begin{array}{l}\text { 95\% Intervalos } \\
\text { de confianza }\end{array}$} \\
\hline & & & & & Bajo & Alto \\
\hline Concertación 89 & 7,310 & 55 & 0,000 & 2,4468 & 1,7760 & 3,1175 \\
\hline Concertación 93 & 7,962 & 59 & 0,000 & 2,4715 & 1,8504 & 3,0926 \\
\hline Concertación 97 & 10,221 & 59 & 0,000 & 2,1938 & 1,7643 & 2,6233 \\
\hline Concertación 01 & 5,527 & 59 & 0,000 & 3,0525 & 1,9473 & 4,1577 \\
\hline
\end{tabular}

Fuente: Cálculos de los autores con datos obtenidos de http://www.elecciones.gov.cl

de no había dos candidatos fuertes. Aunque como discutimos más abajo, el hecho de que la cantidad de candidatos fuertes haya ido disminuyendo con el tiempo, sí parece estar relacionado con la disminución en el número de partidos que conforman la Concertación.

Aunque no podemos aseverar con certeza estadística que la disminución en el número de partidos que componen la Concertación haya reducido el número de distritos donde la coalición de gobierno presenta dos candidatos fuertes, sí hay algunas consideraciones importantes que vale la pena destacar y que subrayan la existencia de una relación entre el número de partidos que componen la coalición de gobierno y la cantidad de distritos donde dicho conglomerado presenta dos candidatos fuertes.

Tanto en 1989 como en 1993, la victoria de la Concertación en las elecciones presidenciales era una cuestión que se daba por sentada muchos meses antes de la inscripción de los candidatos para las elecciones parlamentarias que se celebraban en forma conjunta con la contienda presidencial. En 1997, en cambio, faltaban sólo dos años para la elección presidencial de 1999 y ya se evidenciaba que la coalición de derecha intentaría, por primera vez desde el retorno de la democracia, presentar un candidato que pudiera competir por llegar a La Moneda. Debido a ello, los aspirantes a candidatos de la Concertación sabían que, en caso de resultar perdedores, tendrían sólo 2 años garantizados en que podrían recibir sus 'seguros' desde el Ejecutivo. Ya que no podían tener certeza de quién ganaría las presidenciales de 1999, los aspirantes a candidatos no podían contar con que La Moneda podría garantizarles que sus 'seguros' podrían ser pagados más allá del fin del período del presidente Frei.

En cambio en 2001 faltaban cuatro años para el término del período presidencial de Ricardo Lagos. Aunque entonces las encuestas mostraban 
que la oposición derechista tenía una clara ventaja en la carrera presidencial hacia el 2005, el gobierno de Lagos igual tenía 4 años por delante para pagar el supuesto 'seguro' a los candidatos oficialistas que resultaran perdedores en diciembre de 2001. Más aún, la percepción de que la contienda presidencial de 2005 estaba decidida con tanta antelación sin duda era más extendida en la prensa que en las consideraciones estratégicas de avezados políticos.

Así vistas las cosas, y siguiendo la lógica de Carey y Siavelis, la Concertación se hallaba en inmejorable condición en 2001 para prometer seguro a los ‘subcampeones' que se presentaran al Legislativo y perdieran. Ese año la Concertación tenía la certeza de que mantendrían La Moneda hasta marzo de 2005. En 1997, en cambio, había menos seguridad que en cualquiera de las otras cuatro elecciones. En esa ocasión restaban sólo dos años al período de Frei Ruiz-Tagle. En 1989 y 1993, en cambio, aunque no había certeza absoluta de que la Concertación tendría el control del Ejecutivo, sí habían buenas expectativas de que eso sería cierto por 4 años a partir de 1989 y por 6 años a partir de 1993. Por esa razón, podemos ordenar las cuatro elecciones de acuerdo con la certeza de que la Concertación mantendría el control del Ejecutivo de la siguiente manera:

(mayor certeza) $2001>1993>1989>1997$ (menor certeza)

Ahora bien, la percepción de las posibilidades que tenía la Concertación de retener el control del Ejecutivo más allá del fin del período presidencial vigente en cada elección seguramente variaba entre diferentes aspirantes, por lo que podía haber más aspirantes que hubieran considerado como más probable en 1997 que la Concertación fuera a retener el Ejecutivo después del fin del gobierno de Frei que los que creían lo mismo respecto al sucesor del gobierno de Lagos en 2001. Pero nuestro análisis simplemente se basa en la cantidad de años que quedaban al gobierno y en la certeza de que el Ejecutivo podría darles el 'seguro para los subcampeones’ independientemente del resultado de la próxima elección presidencial.

Así pues, 1997 sería el año en que hubo menos certeza y, por lo tanto, debió haber menos incentivos para que la Concertación pudiera presentar dos candidatos fuertes en la mayoría de los distritos. Pero como muestra el Cuadro $\mathrm{N}^{\circ}$ 5, en 1997 la Concertación presentó un mayor número de duplas fuertes en el país. Inversamente, la menor cantidad de duplas fuertes se presentó en las parlamentarias de 2001, cuando la certeza del control concertacionista del Ejecutivo era la más alta. Ahora bien, como ya señalamos, la diferencia entre el promedio de duplas fuertes en 1997 y 2001 no es estadísticamente significativa. Aunque cabe recordar que Carey y 
CUADRO Nº 6: $\quad$ REELECCIÓN EN CÁMARA DE DIPUTADOS, 1993-2001

\begin{tabular}{lccc}
\hline Año & $\begin{array}{c}\text { Titulares } \\
\text { reelectos }\end{array}$ & $\begin{array}{c}\text { Titulares } \\
\text { no reelectos }\end{array}$ & $\begin{array}{c}\text { Número de titulares } \\
\text { que buscaron la reelección }\end{array}$ \\
\hline 1993 & $71(80,1 \%)$ & $17(19,9 \%)$ & 88 de 120 \\
1997 & $72(85,7 \%)$ & $12(14,3 \%)$ & 84 de 120 \\
2001 & $74(80,4 \%)$ & $18(19,1 \%)$ & 92 de 120 \\
Total & $217(82,2 \%)$ & $47(17,8 \%)$ & 264 de 360 \\
\hline
\end{tabular}

Fuente: Cálculos de los autores con datos de http://www.congreso.cl/

Siavelis no consideran las parlamentarias de 2001 en su análisis, la evidencia de la mayor dificultad que aparentemente habría tenido la Concertación ese año para encontrar duplas fuertes cuestiona el argumento de que la posibilidad de ofrecer 'seguros a los subcampeones' induce a candidatos fuertes a presentarse en las listas de la Concertación.

Por cierto, una posible razón por la que ha disminuido el número de duplas fuertes en la Concertación pudiera tener que ver con la alta tasa de reelección de titulares que se da en la Cámara. El Cuadro $\mathrm{N}^{\circ} 6$ muestra las tasas de reelección para las tres contiendas legislativas en que diputados titulares se presentaron a la reelección. Aunque el número de los diputados que han buscado y han logrado la reelección se ha mantenido estable, el hecho de que más del $80 \%$ de los diputados que buscan la reelección tiene éxito bien pudiera representar un obstáculo lo suficientemente convincente como para inducir a potenciales candidatos a abstenerse de competir, independientemente de los 'seguros' que pueda ofrecer la Concertación.

\section{2. 'Seguro para los subcampeones' en la Alianza}

Otra forma de evaluar el argumento de Carey y Siavelis es analizar lo que ocurre en las listas electorales de la Alianza. De ser cierta, la explicación basada en los 'seguros para los subcampeones' debiera ser consistente también con la presencia de duplas fuertes en la coalición de derecha. Para evaluar si eso ocurre utilizamos el mismo método desarrollado en el análisis para la Concertación, pero con el supuesto inverso. Si la Concertación presenta más duplas de candidatos fuertes cuando tiene más posibilidades de garantizar un 'seguro a los subcampeones', la Alianza debería presentar más duplas de candidatos fuertes cuando la Concertación tiene menos posibilidades de mantener el control del Ejecutivo. 
El Cuadro $\mathrm{N}^{\circ} 7$ contiene pruebas $t$ para una muestra para los resultados de la Alianza en las 4 elecciones parlamentarias del período. Nuevamente, dada la gran varianza que se da entre distritos donde se presentan dos candidatos fuertes y distritos donde se presenta sólo uno, los márgenes de confianza (95\%) son bastante amplios. Así, en 1989, con un 95\% de confianza podemos decir que el verdadero valor de la Razón-Alianza se ubicaba entre un mínimo de 2,44 y un máximo de 4,91. Como es de esperar, los intervalos de confianza para las 4 elecciones se superponen de la misma forma como ocurre en la Concertación. Esto es, no podemos concluir con confianza estadística que la varianza observada en los promedios refleje diferencias de fondo en los distritos donde la Alianza presentó dos candidatos. Aunque, por cierto, si se comparan los valores del Cuadro $\mathrm{N}^{\circ} 7$ (resultados de duplas fuertes de la Alianza) con los del Cuadro $\mathrm{N}^{\circ} 5$ (duplas fuertes de la Concertación), los valores también se superponen dentro del rango de confianza de 95\%, con excepción de 1997. Con confianza estadística podemos decir que ese año la cantidad de duplas fuertes en la Concertación fue mayor que en la Alianza. Esto es, el año en que la Concertación tenía menos tiempo para entregar seguros a sus subcampeones fue cuando más diferencia hubo entre la cantidad de duplas fuertes en la Concertación y la Alianza en elecciones para la Cámara de Diputados.

La incertidumbre de la posibilidad de acceder al 'seguro para los subcampeones' parece no tener incidencia en la posibilidad de que la Concertación presente más duplas fuertes de candidatos en el período. De la misma forma, la variante incertidumbre sobre los resultados de las elecciones tampoco parece tener incidencia en la presencia de duplas de candidatos fuertes en la Alianza. En 1989 la Alianza presentó más duplas fuertes de candidatos que en ningún otro año. Por el contrario, en 1997 el número de duplas fuertes de candidatos fue la menor observada en las 4 elecciones.

CUADRO No 7: $\quad$ PRUEBAS T PARA UNA MUESTRA DE RAZON-ALIANZA, 1989-2001

\begin{tabular}{lcccccc}
\hline & Valor t & $\begin{array}{c}\text { Grados de } \\
\text { libertad }\end{array}$ & $\begin{array}{c}\text { Sig. } \\
\text { (2-tailed })\end{array}$ & $\begin{array}{c}\text { Diferencia } \\
\text { promedio }\end{array}$ & \multicolumn{2}{c}{$\begin{array}{c}\text { 95\% Intervalos } \\
\text { de confianza }\end{array}$} \\
\cline { 5 - 7 } & & & & & & \multicolumn{2}{c}{ Bajo } & Alto \\
\hline Alianza 89 & 5,965 & 58 & 0,000 & 3,676 & 2,4426 & 4,9098 \\
Alianza 93 & 8,489 & 59 & 0,000 & 4,291 & 3,2798 & 5,3028 \\
Alianza 97 & 6,821 & 58 & 0,000 & 5,247 & 3,7072 & 6,7868 \\
Alianza 01 & 7,350 & 58 & 0,000 & 4,753 & 3,4587 & 6,0478 \\
\hline
\end{tabular}


Aunque estas diferencias no son estadísticamente significativas, aparentemente reflejan pocas expectativas por parte de la derecha de ganar las elecciones presidenciales. Por otro lado, esta cifra también pudiera estar reflejando la disminución en el número de partidos que conforman la Alianza. En 1989 esa coalición estaba formada por dos partidos principales y varios partidos menores, amén de un número considerable de independientes (que aquí son agrupados como todos pertenecientes a un solo partido). En la medida en que RN y la UDI se consolidaron como los dos partidos fuertes de la Alianza, y la mayoría de los candidatos comenzó a provenir de las filas de esos dos partidos, el número de duplas fuertes comenzó a disminuir en tanto ambos partidos pudieron negociar omisiones y candidatos privilegiados. De la misma forma, la presencia de diputados titulares que postulaban a la reelección pudo contribuir a disminuir el número de retadores fuertes en la Alianza, generando menos competencia interna en esa coalición.

Así y todo, a menos que la Alianza y la Concertación hayan dado por descontado que la Concertación mantendría siempre el control del Ejecutivo, las expectativas sobre los resultados electorales y la cantidad de tiempo que le restaba al gobierno en el poder parecieran no haber tenido efecto en las consideraciones de RN y la UDI. Creemos que esta evidencia cuestiona la validez del argumento de Carey y Siavelis. Si los partidos de la Concertación actúan racionalmente, ofreciendo ‘seguros' a sus candidatos para que se presenten en elecciones en duplas fuertes, la certidumbre respecto de quién controlará el Ejecutivo en los años posteriores a la elección debió haber tenido un efecto en el número de duplas fuertes que se presentaran. De la misma forma, la posibilidad de acceder al poder en la siguiente elección debió haber tenido influencia en la cantidad de duplas fuertes que se presentaron en la Alianza, pero no fue así.

\subsection{Partidos fuertes y duplas fuertes: Concertación}

Ahora bien, no todos los partidos tienen el mismo peso y la misma importancia electoral. Por ese motivo, reproducimos todo el análisis incluyendo sólo candidatos de 'partidos fuertes', para evaluar si la presencia de más partidos fuertes en cada coalición tiene un efecto sobre la cantidad de duplas fuertes que se presentan a las elecciones. Nuestra hipótesis inicial la refinamos para este análisis. La nueva hipótesis es que mientras más partidos fuertes hay en la coalición, más duplas fuertes presentará en la elección parlamentaria. Definimos como partidos fuertes a los partidos más votados 
y de mayor presencia nacional en cada coalición. Así, en la Concertación existen 3 partidos fuertes: PDC, PPD y PS. A su vez, en la Alianza por Chile existen 2 partidos fuertes: RN y UDI. Además de ser los 5 partidos con más votación a nivel nacional, son los que más presencia tienen en los 60 distritos. Argumentamos que tal vez el mayor número de partidos fuertes en la Concertación pudiera explicar la mayor presencia de duplas fuertes en esa coalición.

Una forma alternativa de abordar esta discusión sería a través del análisis de los subpactos que se forman al interior de la Concertación en vez de analizar los partidos fuertes. Históricamente, uno de los subpactos de la Concertación ha estado conformado por la alianza ocasional entre el PDC y otros partidos y candidatos independientes, mientras que el otro subpacto ha estado conformado por la alianza ocasional entre el PS-PPD y otros partidos y candidatos independientes. Pero si utilizamos los subpactos como unidades de análisis, simplemente estaremos refrendando a través del supuesto inicial (que los subpactos de la Concertación reproducen la unión del centro y de la izquierda) el punto que queremos evaluar, si la Concertación está efectivamente constituida por el ‘tercio del centro' y el ‘tercio de izquierda.' De ahí que optemos por evaluar a los partidos en vez de los subpactos $^{3}$. Por cierto, en la derecha cada uno de los partidos constituye un subpacto, por lo que el análisis de subpactos sería relevante sólo en la Concertación.

El Cuadro No 8 muestra el promedio de la Razón-Concertación para cada elección de la Cámara de Diputados llevada a cabo desde 1989. Sólo consideramos los distritos que presentaron duplas donde ambos candidatos militaban en el PDC, PPD o PS. En 1989, la Concertación presentó un promedio de razón de 1,427, considerando que sólo presentó listas con duplas fuertes en 18 distritos. Para 1993, la Concertación presentó duplas fuertes en 41 distritos, con un promedio de razón 2,074. En 1997, la Concertación presentó duplas fuertes en 50 distritos, obteniendo 2,345 como promedio de razón. Por último, en 2001, la Concertación obtuvo una razón promedio de duplas fuertes de 2,523, en 40 distritos.

Si bien en 1989 sólo en 18 distritos se enfrentaron candidatos del PPD y el PDC (ese año el PS no estaba oficialmente inscrito), la RazónConcertación fue la más baja de las cuatro elecciones. Cuando ingresó el PS

${ }^{3}$ Ahora bien, la adopción de una reforma electoral en 1989 que permitió la formación de coaliciones y una posterior en 1991 que permitió la formación de subpactos en elecciones municipales también puede ser interpretada como evidencia de la persistencia de partidos distinguibles al interior de cada coalición así como de la subsistencia de las tres grandes corrientes — derecha, centro e izquierda - que se consolidaron durante la década de los 60 . 
CUADRO No 8: RAZÓN-CONCERTACIÓN Y PARTIDOS FUERTES DE LA CONCERTACIÓN, 1989-2001

\begin{tabular}{lcccc}
\hline & $\begin{array}{c}\text { Razón-Conc. } \\
1989\end{array}$ & $\begin{array}{c}\text { Razón-Conc. } \\
1993\end{array}$ & $\begin{array}{c}\text { Razón-Conc. } \\
1997\end{array}$ & $\begin{array}{c}\text { Razón-Conc. } \\
2001\end{array}$ \\
\hline Promedio & 1,427 & 2,074 & 2,345 & 2,523 \\
Número de partidos fuertes & 2 & 3 & 3 & 3 \\
Número de distritos & 18 & 41 & 50 & 50 \\
\hline
\end{tabular}

Fuente: Cálculos de los autores con datos obtenidos de http://www.elecciones.gov.cl

a competir como partido oficial en la Concertación, la razón Concertación aumentó levemente (aunque hay que recordar que el PS y el PPD nunca se han enfrentado en un mismo distrito en elecciones parlamentarias).

El Cuadro $N^{\circ} 9$ señala pruebas de pruebas t para una muestra para las 4 elecciones parlamentarias del período. La única elección que presenta resultados estadísticamente diferentes es la contienda de 1989, que tuvo un nivel de competencia sustancialmente superior en las duplas de la Concertación. Ello probablemente se debió a la ausencia de titulares que buscaban la reelección, lo que permitió que las contiendas fueran más peleadas al interior de la lista de la Concertación en muchos más distritos. Pero para el resto de las elecciones los valores no son estadísticamente distinguibles entre sí.

Una comparación con los valores del Cuadro $\mathrm{N}^{\circ} 5$ muestra que cuando eliminamos los candidatos de partidos menores en la Concertación, los valores de la Razón-Concertación disminuyen sustancialmente en todas las

CUADRO N ${ }^{\circ}$ 9: $\quad$ PRUEBAS T PARA UNA MUESTRA DE RAZÓN-CONCERTACIÓN, 1989-2001 (PARTIDOS FUERTES)

\begin{tabular}{lrrrrrr}
\hline & Valor t & $\begin{array}{c}\text { Grados de } \\
\text { libertad }\end{array}$ & $\begin{array}{c}\text { Sig. } \\
\text { (2-tailed) }\end{array}$ & $\begin{array}{c}\text { Diferencia } \\
\text { promedio }\end{array}$ & \multicolumn{2}{c}{$\begin{array}{c}\text { 95\% Intervalos } \\
\text { de confianza }\end{array}$} \\
\cline { 6 - 7 } & & & & & & \\
& & & & & & \\
\hline
\end{tabular}

Fuente: Cálculos de los autores con datos obtenidos de http://www.elecciones.gov.cl 
elecciones. Esto quiere decir que cuando se enfrentan candidatos del bloque PS-PPD con candidatos PDC hay mayor competencia que cuando alguno de los candidatos de la Concertación pertenece a otro partido (PRSD o independiente). Esta observación tiende a fortalecer la hipótesis de que la Concertación tiene más duplas fuertes porque está compuesta de dos de los tres tercios históricos en que se dividía el sistema político chileno.

Tal como lo hicimos anteriormente, podemos aplicar a estos datos el mismo criterio de la 'certeza de mantener el poder' para analizar la presencia de los partidos fuertes en las duplas. En 1989 y 1993 la victoria de la Concertación en las elecciones presidenciales era ampliamente anticipada incluso antes de que se llevara a cabo la conformación de las listas para las parlamentarias. En 1989 había bastantes probabilidades — pero no certeza absoluta — de que la Concertación mantendría el poder del Ejecutivo por 4 años, y en 1993 por 6. El año 1997 es cuando la Concertación tenía menos seguridad del control del Ejecutivo, por faltar sólo 2 años para las elecciones. Como en el 2001 faltaban 4 años para realizar las próximas presidenciales, la Concertación debería haber presentado más duplas fuertes, debido a que es el año en que se encontraba en mejores condiciones para garantizar 'seguros’ a sus posibles subcampeones. Pero el 2001 se da el valor más alto de la Razón-Concertación, al contrario de lo que se esperaba.

A pesar de no existir una diferencia estadística significativa entre los promedios de las razones por año, parece haber una tendencia al aumento de duplas fuertes en la lista de la Concertación cuando eliminamos a los candidatos de partidos menores y sólo consideramos a los candidatos del PDC y del PS-PPD. Estos datos nos muestran cómo la presencia de candidatos de partidos fuertes dentro de las duplas parlamentarias permite presentar listas más fuertes.

\subsection{Partidos fuertes y duplas fuertes: Alianza por Chile}

También analizamos la presencia de duplas de candidatos de partidos fuertes (RN y UDI) en la Alianza por Chile. El Cuadro $N^{\circ} 10$ muestra el promedio de la Razón-Alianza para cada elección de la Cámara de Diputados llevada a cabo desde 1989, considerando sólo los distritos que presentaron duplas conformadas por candidatos de RN y UDI. En 1989 la coalición de derecha presentó duplas fuertes en 37 distritos y obtuvo un promedio de razón de los candidatos de 3,492. En 1993 presentó duplas fuertes en 17 distritos y logró un promedio de razón de 4,448. En 1997, en 40 distritos, logró obtener un promedio de la razón de duplas de candidatos fuertes igual 
CUADRO N 10: RAZÓN-ALIANZA Y NÚMERO DE PARTIDOS FUERTES EN LA ALIANZA, 1989-2001

\begin{tabular}{lcccc}
\hline & $\begin{array}{c}\text { Razón-Alianza } \\
1989\end{array}$ & $\begin{array}{c}\text { Razón-Alianza } \\
1993\end{array}$ & $\begin{array}{c}\text { Razón-Alianza Razón-Alianza } \\
1997\end{array}$ & 2001 \\
\hline Promedio & 3,492 & 4,448 & 6,126 & 5,285 \\
Número de partidos fuertes & 2 & 2 & 2 & 2 \\
Número de distritos & 37 & 17 & 40 & 39 \\
\hline
\end{tabular}

Fuente: Cálculos de los autores con datos obtenidos de http://www.elecciones.gov.cl

a 6,126. Por último, en las elecciones de 2001 presentó duplas de partidos fuertes en 39 distritos y logró una razón promedio de 5,285. Los promedios de razones de la Alianza con candidatos de partidos fuertes aumentan al compararlos con los valores presentados en el Cuadro $\mathrm{N}^{\circ} 7$, cuando se consideran todos los distritos del país. Esto nos demuestra que, al contrario a lo que ocurre en la Concertación, son los independientes y los representantes de partidos menores de la derecha los que ayudan a la Alianza a presentar más duplas fuertes. Ahora bien, esto bien pudiera deberse a que, pese a las aparentes discrepancias y conflictos que existen entre $\mathrm{RN}$ y la UDI, ambos partidos tienden a lograr acuerdos de candidatos privilegiados y omisiones en los distritos donde se presentan titulares a reelección, de tal forma que la competencia real entre candidatos de ambos partidos es menor que lo se pudiera percibir. De hecho, si la mayor competencia se da cuando hay candidatos de partidos menores e independientes enfrentando a algún candidato de RN y la UDI, entonces podemos concluir que las disputas reales entre candidatos de ambos partidos son mucho menos recurrentes que las disputas entre independientes de derecha y algún militante RN o UDI, o incluso que las disputas entre candidatos RN y UDI son menos reñidas que las que se observan entre candidatos del PDC y del bloque PS/ PPD en la Concertación.

Igual que como hicimos con la Concertación, aplicamos una prueba estadística para comprobar si existe una tendencia significativa entre los años de elección y las nuevas razones. A diferencia de lo que ocurre con la Concertación, ninguno de los valores es estadísticamente distinguible. Pero al igual que lo que ocurre en la Concertación, en 1989 hay más competencia, posiblemente producto de la ausencia de diputados titulares que se presentaban a la reelección. Por cierto, los rangos del 95\% de confianza son sumamente amplios, lo que refleja que hubo mucha varianza de distrito en 
CUADRO N 11: PRUEBAS T PARA UNA MUESTRA DE RAZÓN-ALIANZA, 1989-2001 (PARTIDOS FUERTES)

\begin{tabular}{|c|c|c|c|c|c|c|}
\hline & \multirow[t]{2}{*}{ Valor t } & \multirow[t]{2}{*}{$\begin{array}{l}\text { Grados de } \\
\text { libertad }\end{array}$} & \multirow[t]{2}{*}{$\begin{array}{c}\text { Sig. } \\
\text { (2-tailed) }\end{array}$} & \multirow[t]{2}{*}{$\begin{array}{c}\text { Diferencia } \\
\text { promedio }\end{array}$} & \multicolumn{2}{|c|}{$\begin{array}{c}95 \% \text { Intervalos } \\
\text { de confianza }\end{array}$} \\
\hline & & & & & Bajo & Alto \\
\hline Alianza 89 & 4,446 & 36 & 0,000 & 3,491 & 1,898 & 5,084 \\
\hline Alianza 93 & 3,566 & 16 & 0,003 & 4,448 & 1,804 & 7,092 \\
\hline Alianza 97 & 5,832 & 39 & 0,000 & 6,122 & 3,999 & 8,245 \\
\hline Alianza 01 & 5,948 & 38 & 0,000 & 5,285 & 3,486 & 7,085 \\
\hline
\end{tabular}

Fuente: Cálculos de los autores con datos obtenidos de http://www.elecciones.gov.cl

distrito. Mientras en algunos distritos se observaron contiendas altamente competitivas entre los candidatos RN y UDI, en otros existió muy poca competencia. A diferencia de la Concertación, donde las contiendas entre candidatos DC versus candidatos PS-PPD son más reñidas que las instancias donde hay candidatos de partidos menores, en la Alianza la presencia de competencia entre candidatos RN versus UDI no contribuye a que disminuya la Razón-Alianza, esto es, no contribuye a hacer más competitiva la contienda al interior de la dupla Alianza.

La evidencia parece ser concluyente. Mientras la presencia de duplas compuestas por candidatos de partidos fuertes (DC versus PS-PPD) tiende a generar más competencia en la Concertación, la presencia de duplas de candidatos de partidos fuertes en la Alianza tiende a disminuir la competencia al interior de esa coalición política. Esto bien pudiera reflejar que, pese a sus disputas y conflictos, los dos partidos más importantes de la Alianza no compiten demasiado entre sí, logrando pactos de omisiones y candidatos privilegiados que producen mucho menor competencia en esa coalición que la que se observa en la Concertación.

Nuevamente, el fantasma de los tres tercios pareciera hacerse presente para explicar los mayores grados de competencia al interior de la Concertación. Más que la posibilidad de ofrecer 'seguros a los subcampeones' - cuya varianza pareciera no afectar a la cantidad de candidatos fuertes que se animan a presentarse en la lista de la Concertación- pareciera que la presencia de competencia entre el PDC y la izquierda (PS-PPD) es lo que explica la mayor competencia que existe en las duplas de candidatos de la Concertación. A su vez, pese a estar constituida por dos partidos diferentes, la Alianza simplemente reflejaría a un solo sector político, compuesto por dos partidos que, pese a sus diferencias, evitan la competencia abierta. 
El número de partidos parece tener alguna importancia, pero la presencia de candidatos de partidos fuertes pareciera ser el motivo de la mayor competencia (menor valor de Razón-Concertación) en la coalición de gobierno y no en la Alianza. Esto nuevamente fortalece el argumento de que la Concertación tiene más competencia interna porque está compuesta de dos de los tres tercios que porque tiene la capacidad de ofrecer 'seguros' para sus candidatos perdedores.

\section{Conclusión}

En este trabajo hemos planteado dos explicaciones alternativas a la ofrecida por Carey y Siavelis respecto a la presencia de más candidatos fuertes en la Concertación que en la derecha en las elecciones parlamentarias celebradas en Chile desde 1989. Siavelis y Carey sugieren que la Concertación presenta listas con dos candidatos parlamentarios fuertes debido a que puede ofrecer 'seguros' — en la forma de nombramientos presidenciales- a aquellos candidatos que, asumiendo un riesgo personal en favor de la coalición de centro-izquierda, no salen electos. Ya que al momento de escribir su artículo, se esperaba gran incertidumbre sobre los resultados de las presidenciales de 2005, Carey y Siavelis argumentaron que la Concertación tendría mayor dificultad para presentar duplas de candidatos fuertes. Independientemente del grado de incertidumbre que ahora existe respecto de las presidenciales de 2005, hemos presentado dos explicaciones alternativas de por qué la Concertación presenta listas con más candidatos fuertes que la Alianza. La primera consiste en que la Concertación está formada por partidos que representan a dos de los tres tercios históricos de la política chilena. La segunda argumenta que la Concertación simplemente está compuesta de un número superior de partidos que la Alianza. De hecho, nuestro argumento sugiere que la Concertación presenta candidatos fuertes en forma independiente del nivel de incertidumbre que se espera tenga cada elección presidencial.

Pese a que encontramos suficiente evidencia para legitimar nuestras dos explicaciones alternativas, no logramos suficiente confianza estadística o metodológica para plantear que ellas son mejores que las ofrecidas por Carey y Siavelis. Pero de la misma forma hemos argumentado que la explicación planteada por ellos no es metodológica o estadísticamente más plausible que las planteadas por nosotros. Es más, planteamos que de presentar la Concertación duplas fuertes en las próximas elecciones de diciembre de 2005, nuestras hipótesis alternativas tendrán más validez que las de Carey y 
Siavelis. No parece que la incertidumbre sobre el resultado (y la posibilidad de hacer promesas creíbles sobre posibles seguros a los perdedores) explique la presencia de candidatos fuertes en la Concertación. Más bien parece que la naturaleza de la Concertación, compuesta por partidos que representan a dos de los tres tercios de la política chilena, es lo que da cuenta de un mayor número de duplas fuertes en las listas de candidatos de la coalición de centro-izquierda.

\section{REFERENCIAS}

Allamand, Andrés: “Las Paradojas de un Legado”. En Paul Drake e Iván Jaksic (compiladores), El Modelo Chileno. Democracia y Desarrollo en los Noventa. Santiago: LOM, 1999.

Arriagada, Genaro: De la Vía Chilena a la Vía Insurreccional. Santiago: Editorial del Pacífico, 1974.

Boeninger, Edgardo: Democracia en Chile. Lecciones para la Gobernabilidad. Santiago: Editorial Andrés Bello, 1997.

Carey, John M. y Peter Siavelis: “El 'Seguro' para los Subcampeones Electorales y la Sobrevivencia de la Concertación”. En Estudios Públicos, 90, 2003, pp. 5-27.

Cavallo, Ascanio, Óscar Sepúlveda y Manuel Salazar: La Historia Oculta del Régimen Militar. 1973-1988. Santiago: Grijalbo, 1997.

Constable, Pamela y Arturo Valenzuela: A Nation of Enemies. Chile Under Pinochet. New York: Norton, 1991.

De Vylder, Stefan: Allende's Chile: The Political Economy of the Rise and Fall of the Unidad Popular. New York: Cambridge University Press, 1976.

Garretón, Manuel Antonio: El Proceso Político Chileno. Santiago: FLACSO, 1983.

Gil, Federico: El Sistema Político de Chile. Santiago: Editorial Andrés Bello, 1969.

Huneeus, Carlos: Chile, un País Dividido. La Actualidad del Pasado. Santiago: Catalonia, 2003.

Otano, Rafael: Crónica de la Transición. Santiago: Planeta, 1995.

Ortega Frei, Eugenio: Historia de una Alianza. Santiago: CED-CESOC, 1992.

Sartori, Giovanni: Parties and Party Systems: A Framework for Analysis. New York: Cambridge University Press, 1976.

Scully, Timothy: Rethinking the Center. Party Politics in Nineteenth- and TwentiethCentury Chile. Stanford: Standford University Press, 1992.

Scully, Timothy y J. Samuel Valenzuela: "De la Democracia a la Democracia. 1993”. En Estudios Públicos, 51 (invierno), 1993, pp. 195-228.

Tironi, Eugenio y Felipe Agüero: “¿Sobrevivirá el Nuevo Paisaje Político Chileno?” En Estudios Públicos, 74 (otoño), 1999, pp. 151-168.

Urzúa Valenzuela, Germán: Historia Política de Chile y su Evolución Electoral. Desde 1810 a 1992. Santiago: Editorial Jurídica de Chile, 1992.

Valdés, Juan Gabriel: Pinochet's Economists: The Chicago School in Chile. New York: Cambridge University Press, 1995. 
Valenzuela, Arturo: The Breakdown of Democratic Regimes. Chile. Baltimore: John Hopkins University Press, 1978.

Valenzuela, J. Samuel: “Orígenes y Transformaciones del Sistema de Partidos en Chile”. En Estudios Públicos, 58, 1995, pp. 5-80.

Valenzuela, J. Samuel: "Respuesta a Eugenio Tironi y Felipe Agüero. Reflexiones sobre el Presente y Futuro del Paisaje Político Chileno a la Luz de su Pasado”. En Estudios Públicos, 75 (invierno), 1999, pp. 273-290.

Valenzuela, J. Samuel y Timothy Scully: "Electoral Choices and the Party System in Chile”. En Comparative Politics, 29: (4) (July), 1997, pp. 511-527.

Walker, Ignacio: Socialismo y Democracia. Santiago: CIEPLAN, 1990. 